\title{
May clinical neurophysiology help to predict the recovery of neurological early rehabilitation patients?
}

\author{
Jens D. Rollnik
}

\begin{abstract}
Background: So far, the role of clinical neurophysiology in the prediction of outcome from neurological and neurosurgical early rehabilitation is unclear.

Methods: Clinical and neurophysiological data of a large sample of 803 early rehabilitation cases of the BDH-Clinic Hessisch Oldendorf in Northern Germany have been carefully reviewed. Most patients (43.5\%) were transferred to rehabilitation after stroke, mean age was 66.6 (15.5) years. Median somatosensory (SEP), auditory (AEP) and visual evoked potentials (VEP) along with EEG recordings took place within the first two weeks after admission. Length of stay (LOS) in early rehabilitation was 38.3 (37.2) days.

Results: Absence of SEP on one or both sides was associated with poor outcome, $\chi 2=12.98(p=0.005)$; only $12.5 \%$ had a good outcome (defined as Barthel index, $\mathrm{BI} \geq 50$ ) when SEP were missing on both sides. In AEP, significantly longer bilateral latencies III were observed in the poor outcome group $(p<0.05)$. Flash VEP showed that patients in the poor outcome group had a significantly longer latency III on both sides $(p<0.05)$. The longer latency III, the smaller BI changes (Bl discharge minus admission) were observed (latency III right $r=-0.145, p<0.01$; left $r=-0.206, p<0.001$ ). While about half of the patients with alpha EEG activity belonged to the good outcome group (80/159, $50.3 \%$ ), only 39/125 (31.2 \%) with theta and 5/41 (12.2\%) with delta rhythm had a favourable outcome, $x 2=24.2, p<0.001$.

Conclusions: Results from this study suggest that loss of median SEP, prolongation of wave III in AEP and flash-VEP as well as theta or delta rhythms in EEG are associated with poor outcome from neurological early rehabilitation. Further studies on this topic are strongly encouraged.
\end{abstract}

Keywords: Clinical neurophysiology, AEP, VEP, SEP, EEG, Outcome, Prognosis, Early rehabilitation

\section{Background}

Patients entering neurological and neurosurgical early rehabilitation are severely impaired. Morbidity is high [1] and they are suffering from disorders of consciousness $[2,3]$. Early rehabilitation patients are dependent on nursing and may be colonized with multi-drug resistant germs [4, 5]. Frequently, their outcome is poor, but it is quite difficult to predict outcome accurately [3].

The role of clinical neurophysiology, in particular electroencephalography (EEG) and evoked potentials (EP) in predicting outcome of these patients is still unclear.

Correspondence: prof.rollnik@bdh-klinik-hessisch-oldendorf.de Institute for Neurorehabilitation Research ("InFo"), BDH Clinic Hessisch Oldendorf, Hannover Medical School (MHH), Greitstr. 18-28, 31840 Hessisch Oldendorf, Germany
Only a few studies are available on long-term rehabilitation results and clinical neurophysiology. The question is whether clinical neurophysiological techniques may help to distinguish between patients who benefit from neurological early rehabilitation and such who don't. In contrast to imaging techniques, neurophysiological measurements are easy to perform, cheap, safe and available in most rehabilitation facilities.

Most studies focus on rehabilitation outcome of stroke patients (Table 1) [6-16]. With respect to SEP, an absence or amplitude reduction of cortical responses seems to be associated with a poor long-term outcome after stroke $[6,7,10]$. Like with SEP, absence of MEP may indicate poor recovery from stroke $[10,16]$. VEP have also been studied, suggesting that left-right asymmetry may 
Table 1 Studies on long-term outcome of stroke patients involving clinical neurophysiological data

\begin{tabular}{|c|c|c|c|}
\hline Study & $n$ & Methods & Results \\
\hline Zeman \& Yiannikas 1989 [6] & 35 & Median SEP & $\begin{array}{l}\text { Abnormal SEP (absence or amplitude reduction or prolonged } \\
\text { latency N20) were associated with poor outcome (lower BI) after } \\
\text { a mean LOS of } 51 \text { days }\end{array}$ \\
\hline \multirow[t]{2}{*}{ Kovala $1991[7]$} & \multirow[t]{2}{*}{35} & \multirow[t]{2}{*}{ Median and tibial SEP } & $\begin{array}{l}\text { Tibial SEP: correlation between amplitude abnormalities (absence } \\
\text { or attenuation) and occupational outcome after } 1 \text { y }\end{array}$ \\
\hline & & & Median SEP: absence of N60 predicted poor outcome \\
\hline Cillessen et al. 1994 [8] & 55 & EEG in the acute stage & $\begin{array}{l}\text { EEG (presence of delta and theta activity) predicted poor outcome } \\
\text { after } 1 \text { year }\end{array}$ \\
\hline Ring, Bar \& Abboud, 1999 [9] & 4 & VEP & $\begin{array}{l}\text { Correlation between left-right asymmetry of VEP and functional } \\
\text { outcome after a mean of } 137 \text { days inpatient rehabilitation }\end{array}$ \\
\hline Feys et al. 2000 [10] & 64 & $\begin{array}{l}\text { Median SEP and upper } \\
\text { limb MEP }\end{array}$ & $\begin{array}{l}\text { Absence of SEP and MEP indicated poor outcome } 2 \text { months after } \\
\text { stroke }\end{array}$ \\
\hline Steube, Wiethölter \& Correll 2001 [11] & 100 & $\begin{array}{l}\text { Lower limb MEP more than } \\
4 \text { weeks after stroke }\end{array}$ & $\begin{array}{l}\text { Preserved MEP predicted good outcome (independence in walking) } \\
\text { after } 8 \text { weeks of inpatient rehabilitation }\end{array}$ \\
\hline Tzvetanov \& Rousseff 2003 [12]; & \multirow[t]{3}{*}{94} & \multirow[t]{3}{*}{ Median and tibial SEP } & \multirow{3}{*}{$\begin{array}{l}\text { N20-P2 } 25 \text { amplitude is of some predictive value ( } 1 \text { y outcome), but } \\
\text { MRC is stronger predictor of functional outcome, P40 amplitude } \\
\text { correlated with BI ( } r=0.63) \text { after } 3 \text { months }\end{array}$} \\
\hline Tzvetanov, Rousseff, \& Milanov 2003 [13]; & & & \\
\hline Tsetanov, Rousseff \& Atanassova 2005 [14] & & & \\
\hline Al-Rawi, Hamdan \& Abdul-Muttalib 2009 [15] & 22 & Median SEP & $\begin{array}{l}\text { Correlation between SEP (N20 latency and amplitude) and 3-month } \\
\text { outcome (BI, MRC) }\end{array}$ \\
\hline Pizzi et al. 2009 [16] & 52 & Upper limb MEP & $\begin{array}{l}\text { In patients with severe paresis }(M R C<2) \text {, absence of MEP were } \\
\text { predictive of poor recovery }\end{array}$ \\
\hline
\end{tabular}

SEP somatosensory evoked potentials, EEG electroencephalography, MEP motor evoked potentials, VEP visual evoked potentials, BI Barthel index, MRC Medical Research Council (severity of paresis)

be associated with functional outcome [9]. Presence of delta and theta activity in EEG predicted unfavorable outcome one year after stroke [8].

Some studies on long-term outcome of traumatic brain injury (TBI) patients are available (Table 2) [17-23]. While AEP may be of some prognostic value in this group of patients $[17,18]$, most studies focus on SEP. Like with stroke, TBI patients with a loss of cortical SEP-responses seem to have a poor outcome [22].

There are also studies on long-term outcome of disorders of consciousness (DOC) patients, in particular after hypoxic brain damage (Table 3) [3, 24-28]. Results on the question whether SEP or AEP may be used to predict recovery are controversial [24-27]. EEG could be of some value [28]. Latest results from our group suggest that prolongation of wave III in flash VEP, theta or delta rhythm in EEG, and N20/P25 amplitude reduction in median SEP may be associated with poor outcome of hypoxic brain damage patients undergoing neurological early rehabilitation [3].

The present study tried to figure out whether clinical neurophysiology may help to improve outcome prediction of a large cohort of neurological and neurosurgical early rehabilitation patients.

Table 2 Studies on long-term outcome of traumatic brain injury (TBI) patients involving clinical neurophysiological data

\begin{tabular}{|c|c|c|c|}
\hline Study & $n$ & Methods & Results \\
\hline Mackey-Hargadine \& Hall 1985 [17] & 114 & AEP & $\begin{array}{l}\text { Significant correlation between AEP, pupil reactivity and outcome } \\
\text { in a } 24 \text { month period }\end{array}$ \\
\hline Shin et al. 1989 [18] & 29 & AEP and SEP & SEP helped to improve prediction of outcome 12 months after TBI \\
\hline Thatcher et al. 1991 [19] & 162 & EEG and AEP & $\begin{array}{l}\text { Combination of EEG and GCS bet predicted outcome } 12 \text { months } \\
\text { after TBI }\end{array}$ \\
\hline Mazzini et al. 1999 [20] & 27 & $\begin{array}{l}\text { SEP and MEP from upper and } \\
\text { lower limbs }\end{array}$ & $\begin{array}{l}\text { Clinical and functional outcome was strongly correlated with } \\
\text { abnormalities from tibial SEP, } 6 \text { and } 12 \text { months after TBI }\end{array}$ \\
\hline Özbudak-Demir et al. 1999 [21] & 26 & Median and tibial SEP & $\begin{array}{l}\text { Normal SEP latencies were associated with better outcome, more } \\
\text { than } 8 \text { months after TBI }\end{array}$ \\
\hline Lew et al. 2003 [22] & 22 & Median SEP & $\begin{array}{l}\text { Bilateral absence of SEP was strongly predictive of worst outcome } \\
\text { (death or vegetative state), } 6 \text { months after TBI }\end{array}$ \\
\hline Houlden et al. 2010 [23] & 81 & Median SEP & SEP within 7 days after TBI correlate with 1 y outcome \\
\hline
\end{tabular}

$T B I$ traumatic brain injury, SEP somatosensory evoked potentials, AEP auditory evoked potentials, EEG electroencephalography, MEP motor evoked potentials 
Table 3 Studies on long-term outcome of DOC (disorders of consciousness) patients due to hypoxic or severe brain damage of different origin involving clinical neurophysiological data

\begin{tabular}{|c|c|c|c|}
\hline Study & $n$ & Methods & Results \\
\hline Zeitlhofer et al. 1991 [24] & 22 & AEP and SEP & Evoked potentials had no value for the prognosis of "apallic" patients \\
\hline Goldberg \& Karazim 1998 [25] & 33 & AEP and SEP & AEP and SEP predicted outcome of MCS patients \\
\hline Howell et al. 2013 [26] & 113 & SEP & SEP did not predict outcome of hypoxic brain damage survivors \\
\hline Schorl, Valerius-Kukula \& Kemmer 2014 [27] & 28 & Median SEP & Bliateral loss of SEP did not exclude recovery from severe brain damage \\
\hline Bagnato et al. 2015 [28] & 101 & EEG & $\begin{array}{l}\text { Reduced EEG amplitudes and delta frequencies were associated with bad } \\
\text { clinical outcome (UWS, MCS) }\end{array}$ \\
\hline Heinz \& Rollnik 2015 [3] & 93 & $\begin{array}{l}\text { EEG, flash VEP, } \\
\text { median SEP }\end{array}$ & $\begin{array}{l}\text { Prolongation of wave III (flash VEP), theta or delta EEG rhythm and } \\
\text { N20/P25-amplitude reduction (SEP) predicted poor outcome }(\mathrm{BI}<50)\end{array}$ \\
\hline
\end{tabular}

SEP somatosensory evoked potentials, $A E P$ auditory evoked potentials, EEG electroencephalography, VEP visual evoked potentials, $B I$ Barthel index, UWS unresponsive wakefulness syndrome, MCS minimally conscious state

\section{Methods}

\section{Patients}

Medical records of 803 patients (376 female, 436 male) of the BDH-Clinic Hessisch Oldendorf, a large neurological and neurosurgical early rehabilitation facility located in Northern Germany, have been analyzed. Patients were admitted in 2010. Main diagnoses are presented in Table 4. The main diagnosis was defined according to the G-DRG- (German Diagnosis Related Groups) system as the disease justifying referral for early rehabilitation. When stroke patients also suffered from a peripheral disorder like diabetic polyneuropathy, for instance, stroke was defined as main diagnosis because it necessitated rehabilitation treatment.

Most patients underwent early rehabilitation after stroke ( $n=349,43.5 \%), 34.0$ (208.6) days after disease onset. Mean age was 66.6 (15.5) years. Length of stay (LOS) in early rehabilitation was 38.3 (37.2) days, LOS of the whole rehabilitation 58.5 (52.4) days. Discharge placement: $52.2 \%(419 / 803)$ underwent subsequent rehabilitation or went home, $31.5 \%(253 / 803)$ were discharged to a nursing home, $11.3 \%(91 / 803)$ needed acute-care hospital treatment and $4.7 \%$ (38/803) died.

Table 4 Main diagnoses

\begin{tabular}{lll}
\hline & Number & Percent \\
\hline Stroke & 349 & 43.5 \\
Intracerebral bleeding & 107 & 13.3 \\
Subarachnoidal bleeding & 65 & 8.1 \\
Hypoxic brain damage & 37 & 3.4 \\
Polyneuropathy, GBS & 24 & 3.0 \\
Brain tumor & 23 & 2.9 \\
Traumatic brain injury & 21 & 2.6 \\
Spinal trauma & 13 & 1.6 \\
Meningitis, encephalitis & 10 & 1.2 \\
Other main diagnosis & 154 & 19.2 \\
Sum & 803 & 100 \\
\hline
\end{tabular}

One patient was discharged against medical advice and another one was transferred to a hospice.

\section{Clinical scales and assessments}

On admission and at discharge, Barthel index (BI) [29] and Early Rehabilitation Index (ERI) [30] have been obtained. In line with previous studies, poor outcome was defined as a $\mathrm{BI}<50$ points [3]. In addition, CRS [31], GCS [32] and Early Functional Abilities scale [33] have been analyzed.

\section{Clinical neurophysiology}

Electroencephalography (EEG), auditory evoked potentials (AEP), visual evoked potentials (VEP), somatosensory evoked potentials (SEP) of the median nerve were recorded usually within the first two weeks after admission. EEG was done using the international 10/20 system (Neurofax EEG 9000, Nihon Kohden Europe, Rosbach, Germany). Surface electrodes were used for evoked potentials (Nicolet Viking Select, Natus Medical, Middleton, WI, USA). VEPs were recorded with flashing light-emitting diodes (flash VEP, stimulation frequency $1.3 \mathrm{~Hz}$ ). Latencies and amplitudes of wave I-III were examined according to the guidelines of the American Clinical Neurophysiology Society [34]. Further, AEP latencies I-V and N20/P25 latencies and amplitudes of median nerve SEPs were analyzed. Neurophysiological examinations were performed by an experienced team of only four paramedics working in this field for many years.

\section{Ethics}

This is a retrospective data analysis, only (no intervention). Local ethics committee of the BDH-Clinic Hessisch Oldendorf gave approval to use facility's data. Patient records/information were anonymized and de-identified prior to analysis. No written informed consent for participation was obtained (retrospective data analysis, no intervention). 


\section{Statistics}

For statistical analyses, SPSS ${ }^{\mathrm{m}} 21.0$ software package (SPSS Inc, Chicago, USA) was used. In the results section, mean values and standard deviations (in brackets) are displayed. In parametric (t-tests for independent samples and analysis of variance) as well as nonparametric tests $\left(\chi^{2}\right.$-tests), differences were regarded as significant with $p<0.05$. In addition, bivariate Pearson correlations were computed.

\section{Results}

Poor outcome patients were significantly older, had more co-diagnoses, a longer LOS, lower BI, ERI, GCS and CRS on admission (Table 5).

\section{Imaging data}

Computed tomography (CT) and/or magnetic resonance imaging (MRI) of the skull was available in about $2 / 3$ of cases (Table 6). Most frequent lesion sites were temporal, parietal and frontal lobes.

\section{Median SEP}

Median SEP data was available in 449 cases (55.9 \%). Loss of cortical SEP on one or both sides was associated with poor outcome (Table 7), $\chi^{2}=12.98 \quad(p=0.005)$. While 153/353 (43.3\%) had a good outcome when SEP were present, only $26.3 \%(21 / 80)$ belonged to the good outcome group when SEP were absent on one side and $12.5 \%(2 / 16)$ when SEP were absent on both sides.

Table $\mathbf{5}$ Characteristics of neurological early rehabilitation patients with good and poor outcome

\begin{tabular}{lccc}
\hline & $\begin{array}{l}\text { good } \\
\text { outcome }\end{array}$ & $\begin{array}{l}\text { poor } \\
\text { outcome }\end{array}$ & p-value* \\
\hline Age [years] & $62.4(15.7)$ & $69.0(14.7)$ & $<0.001$ \\
$\begin{array}{l}\text { LOS - neurological early } \\
\text { rehabilitation [days] }\end{array}$ & $27.8(38.0)$ & $46.1(35.3)$ & $<0.001$ \\
Number of co-diagnoses [n] & $13.0(5.4)$ & $16.6(5.5)$ & $<0.001$ \\
$\begin{array}{l}\text { Barthel Index (BI) on admission } \\
\text { [0 to 100] }\end{array}$ & $33.0(28.5)$ & $14.4(8.2)$ & $<0.001$ \\
$\begin{array}{l}\text { Barthel index at discharge } \\
\text { [0 to 100] }\end{array}$ & $76.5(16.6)$ & $20.7(10.7)$ & $<0.001$ \\
$\begin{array}{l}\text { Delta BI (discharge minus } \\
\text { admission) }\end{array}$ & $43.5(25.7)$ & $6.3(9.9)$ & $<0.001$ \\
$\begin{array}{l}\text { Early Rehabilitation Index } \\
\text { (ERI) on admission [-325 to 0] }\end{array}$ & $-46.5(49.3)$ & $-59.1(53.6)$ & 0.001 \\
$\begin{array}{l}\text { ERI at discharge [-325 to 0] } \\
\text { Coma Remission Scale (CRS) }\end{array}$ & $-14.8(23.9)$ & $-38.5(46.2)$ & $<0.001$ \\
[0 to 24] & $15.9(6.3)$ & $10.1(6.4)$ & $<0.001$ \\
$\begin{array}{l}\text { Glasgow Coma Scale (GCS) on } \\
\text { admission [3 to 15] }\end{array}$ & $12.8(2.9)$ & $10.1(3.6)$ & $<0.001$ \\
$\begin{array}{l}\text { Glasgow Coma Scale (GCS) at } \\
\text { discharge [3 to 15] }\end{array}$ & $14.4(0.5)$ & $11.9(3.6)$ & n.S. \\
\hline
\end{tabular}

*t-tests for independent samples, n.s. not significant $(p>0.05)$
Table 6 Imaging results (lesion site)

\begin{tabular}{lllll}
\hline Brain region & Left & Right & Bilateral & Sum \\
\hline Temporal lobe & $106(13.2 \%)$ & $115(14.3 \%)$ & $39(4.9 \%)$ & $260(32.4 \%)$ \\
Parietal lobe & $76(9.5 \%)$ & $127(15.8 \%)$ & $42(5.2 \%)$ & $245(30.5 \%)$ \\
Frontal lobe & $41(5.1 \%)$ & $57(7.1 \%)$ & $53(6.6 \%)$ & $151(18.8 \%)$ \\
Occipital lobe & $25(3.1 \%)$ & $29(3.6 \%)$ & $24(3.0 \%)$ & $78(9.7 \%)$ \\
Brain stem & $16(2.0 \%)$ & $17(2.1 \%)$ & $27(3.4 \%)$ & $60(7.5 \%)$ \\
Cerebellum & $12(1.5 \%)$ & $17(2.1 \%)$ & $14(1.7 \%)$ & $43(5.3 \%)$ \\
\hline
\end{tabular}

Neither N20 or P25 latencies, nor SEP amplitudes were different between good and poor outcome group (Table 8). The age of patients with loss of SEP on one or both sides compared to those with no absence of SEP did not differ significantly $(F=2.213, p>0.05)$.

\section{AEP}

AEP data was available in 448 cases (55.8\%). Absence of AEP on one side was observed in two cases, bilateral loss of AEP responses in one case, only. All three cases belonged to the poor outcome group, but due to small sample size, $\chi^{2}$-test did not reveal significant differences. When comparing poor and good outcome groups, it turned out that a significantly longer latency III was observed on both sides in the poor outcome group $(p<0.05)$, Table 8 . Latency IV also showed significant differences between the groups, but on the left side, only $(p<0.05)$. Since AEP are closely connected to brain stem function, a sub-analysis focusing on brain stem lesions was done: 60 patients with brainstem lesions $(7.5 \%)$ were identified. With intact brain stem, BI at discharge was significantly higher than in patients with unior bilateral lesion $(F=3.931, p=0.009)$. Further, there was a small but significant correlation between age and AEP latency III (left: $r=0.209, p<0.001$; right: $r=0.132, p<0.01$ ).

\section{VEP}

Flash VEP data was available in 391 cases (48.7 \%). Loss of cortical VEP was detected in six cases on one and in four cases on both sides, only. All bilateral loss cases belonged to the poor outcome group. With unilateral absence, 4/6 $(66.6 \%)$ had a poor outcome. Like with AEP, these differences did not reach a level of significance due to small group size. Patients belonging to the poor outcome group had a significantly longer flash VEP latency III on both

Table 7 Absence of median SEP on one or both sides and outcome categories

\begin{tabular}{lllllll}
\hline & \multicolumn{4}{l}{ Absence of median SEP } & Sum \\
\cline { 2 - 5 } Outcome & none & absence right & absence left & bilateral absence & \\
\hline Poor & 200 & 24 & 35 & 14 & 273 \\
Good & 153 & 9 & 12 & 2 & 176 \\
Sum & 353 & 33 & 47 & 16 & 449 \\
\hline
\end{tabular}


Table 8 Data of evoked potentials

\begin{tabular}{|c|c|c|c|c|}
\hline \multirow[t]{2}{*}{ Outcome } & \multicolumn{2}{|l|}{ GOOD } & \multicolumn{2}{|l|}{ POOR } \\
\hline & Left & Right & Left & Right \\
\hline \multicolumn{5}{|c|}{ Auditory evoked potentials (AEP) } \\
\hline Latency I [ms] & $1.71(0.18)$ & $1.70(0.18)$ & $1.72(0.20)$ & $1.73(0.19)$ \\
\hline Latency II [ms] & $2.82(0.24)$ & $2.84(0.27)$ & $2.84(0.25)$ & $2.83(0.25)$ \\
\hline Latency III [ms] & $3.95(0.25)^{*}$ & $3.95(0.25)^{* *}$ & $4.01(0.26)^{*}$ & $4.02(0.27)^{* *}$ \\
\hline Latency IV [ms] & $5.09(0.32)^{*}$ & $5.09(0.29)$ & $5.15(0.33)^{*}$ & $5.12(0.33)$ \\
\hline Latency V [ms] & $5.93(0.32)$ & $5.95(0.30)$ & $5.95(0.32)$ & $5.98(0.32)$ \\
\hline \multicolumn{5}{|c|}{ Visual evoked potentials (flash VEP) } \\
\hline Latency I [ms] & $52.7(15.7)$ & $53.2(14.5)$ & $52.4(13.7)$ & $52.8(13.2)$ \\
\hline Latency II [ms] & $75.7(17.3)$ & $77.1(15.9)$ & $78.2(16.9)$ & $78.6(16.0)$ \\
\hline Latency III [ms] & $108.1(20.7)^{*}$ & $110.2(20.2)^{*}$ & $115.2(21.1)^{*}$ & $115.5(19.6)^{*}$ \\
\hline Amplitude $\mathrm{I} / \mathrm{II}[\mu \mathrm{V}]$ & $8.3(7.9)$ & $8.7(8.2)$ & $7.9(6.2)$ & $8.3(6.2)$ \\
\hline \multicolumn{5}{|c|}{ Somatosensory evoked potentials (SSEP) of the median nerve } \\
\hline $\mathrm{N} 20$ [ms] & $21.0(1.8)$ & $20.8(2.5)$ & $21.1(2.1)$ & $21.1(1.9)$ \\
\hline P25 [ms] & $26.1(2.7)$ & $26.3(3.2)$ & $25.7(3.0)$ & $26.2(3.1)$ \\
\hline Amplitude N20/P25 [ $\mu \mathrm{V}]$ & $3.7(2.4)$ & $3.9(3.0)$ & $4.0(3.7)$ & $3.8(4.0)$ \\
\hline
\end{tabular}

Significant differences between subjects with good and poor outcome are indicated as follows: ${ }^{*} p<0.05$, ${ }^{* *} p<0.01$ (t-tests for independent samples)

sides $(p<0.05)$, Table 8 . The longer latency III, the smaller BI changes (BI discharge minus admission) could be observed (latency III right $r=-0.145, p<0.01$; left $r=-0.206$, $p<0.001)$. As with AEP, there was a small but significant correlation between age and VEP latency III (left: $r=$ $0.166, p<0.01$; right: $r=0.136, p<0.01)$.

\section{EEG}

EEG recordings were available in 360 cases (44.8\%). EEG with alpha, theta or delta frequency was included in the analysis, Table 9. While about half of the patients with alpha activity belonged to the good outcome group $(80 / 159,50.3 \%)$, only $39 / 125(31.2 \%)$ with theta activity and $5 / 41(12.2 \%)$ with delta rhythm had a favorable outcome, $\chi^{2}=24.2, p<0.001$. In ANOVAs, BI was significantly lower on admission and discharge when patients had theta or delta rhythms compared to alpha activity $(p<0.001)$. BI changes (BI discharge minus admission) were also smaller when patients had delta or theta activity, Fig. 1. The age of patients with alpha, theta or delta activity did not differ significantly $(F=1.274, p>0.05)$.

Table 9 EEG activity and outcome

\begin{tabular}{lllll}
\hline & \multicolumn{4}{l}{ EEG frequency } \\
\cline { 2 - 5 } Outcome & Alpha & Theta & Delta & Sum \\
\hline Poor & 79 & 86 & 36 & 201 \\
Good & 80 & 39 & 5 & 124 \\
Sum & 159 & 125 & 41 & 325 \\
\hline
\end{tabular}

\section{Discussion}

So far, reliable data on the usefulness of neurophysiological measurements in predicting the outcome from neurological and neurosurgical early rehabilitation is lacking. The present study analysed data of a large sample 803 patients. One would opt for clinical neurophysiology as a predictor because it is cheap, safe (no radiation), easy to perform and available in most rehabilitation facilities (in contrast to imaging like CT or MRI).

As with previous studies, present results suggest that outcome of neurological early rehabilitation patients mainly depends on age, morbidity and functional status on admission [3]. However, neurophysiological data may be of some predictive value, in particular median SEP, AEP, flash VEP and EEG.

It turned out that patients with worse outcome had longer AEP III latencies. AEP wave III represents the cochlear nucleus which is located in the pontomedullary junction of the dorsolateral brainstem [35]. It is well known that brainstem lesions are associated with poor neurological outcome and fatality [36]. This finding could be reproduced in this study: Subjects with brain stem lesions on one or both sides showed a worse functional outcome from neurological early rehabilitation. As yet, a prolongation of AEP wave III latency has not been identified as a predictor of poor outcome and is a novel finding. Age, however, correlated significantly with wave III latency. Since age is a well-known predictor of poor outcome in neurological rehabilitation [3], it may partially explain this finding. In addition, it has to be 


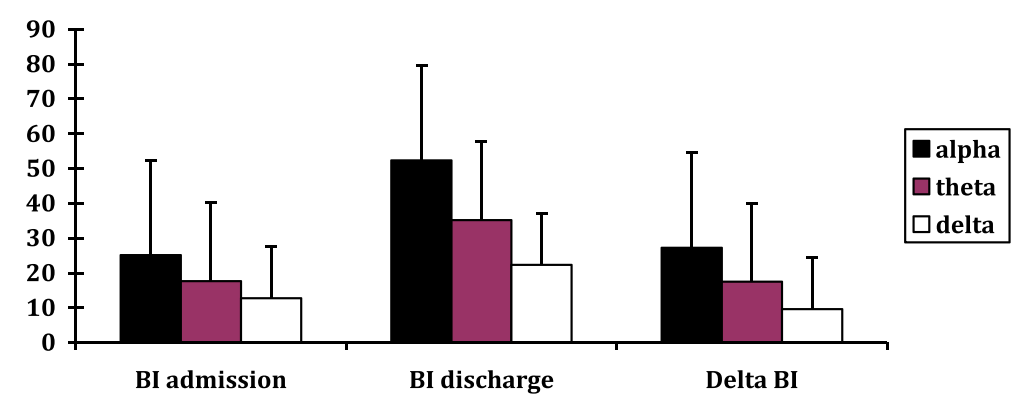

Fig. 1 When patients had alpha EEG-activity, BI on admission, at discharge and changes of BI (discharge minus admission) were significantly higher than patients with theta or delta activity (ANOVAs with LSD-tests, $p<0.001$ )

pointed out that even in the normal ageing brain, a delay of evoked potentials, in particular VEP and AEP, may be observed [37, 38].

Another finding of this study was a prolongation of wave III in flash VEP in the poor outcome group. This finding is in line with a previous study from our group which focused on hypoxic brain damage patients [3]. VEP wave III abnormalities might be a neurophysiological correlate of cortical dysfunction [3]. As with AEP, VEP wave III latency also correlated with age. Thus, age might influence AEP wave III, too.

Another finding was that loss of cortical median SEP responses on one or both sides was associated with poor outcome. We know from literature that long-term outcome of stroke patients is also worse with absent SEP $[6,10]$. Thus, it may be hypothesized that absence of SEP indicates poor outcome in early rehabilitation patients.

There are a couple of studies focusing on EEG and outcome prediction. As with previous studies $[3,8]$, theta and delta activity was associated with poor outcome.

There are some limitations to this study. First of all, this was a retrospective data analysis, only. This explains why only a proportion of the sample has been studied with all four neurophysiological examinations (EEG, SEP, AEP, VEP). Secondly, the patients showed a wide heterogeneity. This, however, is a common finding when examining neurological early rehabilitation patients [1]. These patients suffer from a broad specter of neurological and neurosurgical disorders, central as well as peripheral disturbances. In addition, the study employed no control group and confounding medication (e.g. neuroleptics, benzodiazepines) has not been included in the analysis. Sedatives, however, are rarely used in our rehabilitation facility.

Results from this study defy ready summary, but EEG, median SEP, AEP and flash VEP may be of some predictive value in early rehabilitation patients. Further studies are strongly encouraged.

\section{Conclusion}

Results from this study suggest that loss of median nerve SEP, prolongation of wave III in early AEP and flash-
VEP, as well as theta or delta rhythms in EEG are associated with poor outcome from neurological early rehabilitation. Clinical neurophysiology may help to improve outcome prediction of neurological and neurosurgical rehabilitation patients. EEG and evoked potentials are widely-used, cheap, easy to perform and non-invasive.

\section{Abbreviations}

AEP: Auditory evoked potentials; BI: Barthel index; CRS: Coma remission scale; $C T$ : Computed tomography; DOC: Disorders of consciousness;

EEG: Electroencephalography; EFA: Early functional abilities; EP: Evoked potentials; ERI: Early rehabilitation index; GCS: Glasgow coma scale;

LOS: Length of stay; MEP: Motor evoked potentials; MRI: Magnetic resonance imaging; SEP: Somatosensory evoked potentials; TBI: Traumatic brain injury; VEP: Visual evoked potentials.

\section{Competing interests}

The author declares that he has no competing interests.

\section{Acknowledgements}

The author thanks Ms. Pauline Scholz, study nurse, for preparation of the data base.

Received: 22 September 2015 Accepted: 16 November 2015 Published online: 21 November 2015

\section{References}

1. Rollnik JD, Janosch U. Current trends in the length of stay in neurological early rehabilitation. Dtsch Arztebl Int. 2010;107:286-92.

2. Rollnik JD, Altenmüller E. Music in disorders of consciousness. Front Neurosci. 2014;8:190.

3. Heinz U, Rollnik JD. Outcome of hypoxic brain damage patients undergoing neurological early rehabilitation. BMC Res Notes. 2015;8:243.

4. Rollnik JD. Outcome of MRSA carriers in neurological early rehabilitation. BMC Neurol. 2014;14:34.

5. Rollnik JD. Outcome of neurological early rehabilitation patients colonized with extended-spectrum beta-lactamase (ESBL) producing bacteria. Open Journal of Therapy and Rehabilitation. 2015;3:1-8.

6. Zeman BD, Yiannikas C. Functional prognosis in stroke: use of somatosensory evoked potentials. J Neurol Neurosurg Psychiatry. 1989;52: 242-7.

7. Kovala T. Prognostic significance of somatosensory potentials evoked by stimulation of the median and posterior tibial nerves: a prospective 1-year follow-up study in patients with supratentorial cerebral infarction. Eur Neurol. 1991;31:141-8.

8. Cillessen JP, van Huffelen AC, Kappelle LJ, Algra A, van Gijn J. Electroencephalography improves the prediction of functional outcome in the acute stage of cerebral ischemia. Stroke. 1994;25:1968-72.

9. Ring H, Bar L, Abboud S. Functional correlates with left-right asymmetry of visual evoked potentials in stroke patients: modeling and experimental results. Arch Phys Med Rehabil. 1999;80:166-72. 
10. Feys H, Van Hees J, Bruyninckx F, Mercelis R, De Weerdt W. Value of somatosensory and motor evoked potentials in predicting arm recovery after a stroke. J Neurol Neurosurg Psychiatry. 2000;68:323-31.

11. Steube D, Wiethölter S, Correll C. Prognostic value of lower limb motor evoked potentials for motor impairment and disability after 8 weeks of stroke rehabilitation-a prospective investigation of 100 patients. Electromyogr Clin Neurophysiol. 2001;41:463-9.

12. Tzvetanov P, Rousseff RT. Median SSEP changes in hemiplegic stroke: long-term predictive values regarding ADL recovery. Neuro Rehabilitation. 2003:18:317-24.

13. Tzvetanov P, Rousseff RT, Milanov I. Lower limb SSEP changes in strokepredictive values regarding functional recovery. Clin Neurol Neurosurg. 2003;105:121-7.

14. Tzvetanov P, Rousseff RT, Atanassova P. Prognostic value of median and tibial somatosensory evoked potentials in acute stroke. Neurosci Lett. 2005; 380:99-104.

15. Al-Rawi MA, Hamdan FB, Abdul-Muttalib AK. Somatosensory evoked potentials as a predictor for functional recovery of the upper limb in patients with stroke. J Stroke Cerebrovasc Dis. 2009;18:262-8.

16. Pizzi A, Carrai R, Falsini C, Martini M, Verdesca S, Grippo A. Prognostic value of motor evoked potentials in motor function recovery of upper limb after stroke. J Rehabil Med. 2009;41:654-60.

17. Mackey-Hargadine JR, Hall 3rd JW. Sensory evoked responses in head injury. Cent Nerv Syst Trauma. 1985;2:187-206.

18. Shin DY, Ehrenberg B, Whyte J, Bach J, DeLisa JA. Evoked potential assessment: utility in prognosis of chronic head injury. Arch Phys Med Rehabil. 1989;70:189-93.

19. Thatcher RW, Cantor DS, McAlaster R, Geisler F, Krause P. Comprehensive predictions of outcome in closed head-injured patients. The development of prognostic equations. Ann N Y Acad Sci. 1991;620:82-101.

20. Mazzini L, Pisano F, Zaccala M, Miscio G, Gareri F, Galante M. Somatosensory and motor evoked potentials at different stages of recovery from severe traumatic brain injury. Arch Phys Med Rehabil. 1999;80:33-9.

21. Özbudak-Demir S, Akyüz M, Güler-Uysal F, Orkun S. Postacute predictors of functional and cognitive progress in traumatic brain injury: somatosensory evoked potentials. Arch Phys Med Rehabil. 1999;80(3):252-7.

22. Lew HL, Dikmen S, Slimp J, Temkin N, Lee EH, Newell D, et al. Use of somatosensory-evoked potentials and cognitive event-related potentials in predicting outcomes of patients with severe traumatic brain injury. Am J Phys Med Rehabil. 2003;82:53-61.

23. Houlden DA, Taylor AB, Feinstein A, Midha R, Bethune AJ, Stewart CP, et al. Early somatosensory evoked potential grades in comatose traumatic brain injury patients predict cognitive and functional outcome. Crit Care Med. 2010;38:167-74.

24. Zeitlhofer J, Steiner M, Oder W, Obergottsberger S, Mayr N, Deecke L. The prognostic value of evoked potentials in early neurologic rehabilitation of patients with the apallic syndrome. EEG EMG Z Elektroenzephalogr Elektromyogr Verwandte Geb. 1991;22:10-4.

25. Goldberg G, Karazim E. Application of evoked potentials to the prediction of discharge status in minimally responsive patients: a pilot study. J Head Trauma Rehabil. 1998;13:51-68.

26. Howell K, Grill E, Klein AM, Straube A, Bender A. Rehabilitation outcome of anoxic-ischaemic encephalopathy survivors with prolonged disorders of consciousness. Resuscitation. 2013;84:1409-15.

27. Schorl M, Valerius-Kukula SJ, Kemmer TP. Median-evoked somatosensory potentials in severe brain injury: does initial loss of cortical potentials exclude recovery? Clin Neurol Neurosurg. 2014;123:25-33.

28. Bagnato S, Boccagni C, Sant'Angelo A, Prestandrea C, Mazzilli R, Galardi G. EEG predictors of outcome in patients with disorders of consciousness admitted for intensive rehabilitation. Clin Neurophysiol. 2015;126:959-66.

29. Mahoney Fl, Barthel DW. Functional evaluation: The Barthel index. Md State Med J. 1965;14:61-5.

30. Rollnik JD. The Early Rehabilitation Barthel Index (ERBI). Rehabilitation (Stuttg). 2011;50:408-11.

31. Ortega-Suhrkamp E, von Wild KR. Standards of neurologic-neurosurgical early rehabilitation-a concept of the study group neurological-neurosurgical early rehabilitation. Acta Neurochir Suppl. 2002;79:11-9.

32. Teasdale $G$, Jennett $B$. Assessment of coma and impaired consciousness. A practical scale. Lancet. 1974;2:81-3.

33. Hankemeier A, Rollnik JD. The Early Functional Abilities (EFA) scale to assess cognitive, sensorimotor, oro-facial and vegetative progress of neurological and neurosurgical early rehabilitation patients. BMC Neurology. 2015 (in review).

34. American Clinical Neurophysiology Society. Guideline 9B: Guidelines on Visual Evoked Potentials. 2008.

35. Mukerji S, Windsor AM, Lee DJ. Auditory brainstem circuits that mediate the middle ear muscle reflex. Trends Amplif. 2010;14:170-91.

36. Beier AD, Dirks PB. Pediatric brainstem hemorrhages after traumatic brain injury. J Neurosurg Pediatr. 2014;14:421-4.

37. Chu NS. Age-related latency changes in the brain-stem auditory evoked potentials. Electroencephalogr Clin Neurophysiol. 1985;62:431-6.

38. Shaw NA. Changes in the cortical components of the visual evoked potential with age in man. Aust J Exp Biol Med Sci. 1984;62:771-8.

\section{Submit your next manuscript to BioMed Central and we will help you at every step:}

- We accept pre-submission inquiries

- Our selector tool helps you to find the most relevant journal

- We provide round the clock customer support

- Convenient online submission

- Thorough peer review

- Inclusion in PubMed and all major indexing services

- Maximum visibility for your research

Submit your manuscript at www.biomedcentral.com/submit 